\title{
Defaced and Destructed Calyces in Aboriginal Genitourinary Tuberculosis
}

\section{Manjeet Kumar* | Kirti Rana}

\section{*Correspondence: Manjeet Kumar}

Address: ${ }^{1}$ Assistant Professor, Department of Urology IGMC. HP, India; ${ }^{2}$ Senior Resident, Department of Urology IGMC, HP, India

e-mail $\bowtie$ : manjeetkumar.1014@gmail.com

Received: 21 September 2021; Accepted: 07 October 2021

Copyright: (C) 2021 Manjeet K. This is an open-access article distributed under the terms of the Creative Commons Attribution License, which permits unrestricted use, distribution, and reproduction in any medium, provided that the original work is properly cited.

\section{Clinical Image}

A 42 years female presented with frequency, low-grade fever, and flank pain. On evaluation blood investigations were normal. On urine, microscopy showed plenty of pus cells and urine culture was sterile. Ultrasound showed right bilateral normal kidney with right mild hydronephrosis. Intravenous pyelography (IVP) was done which suggested the right Kidney having irregular distorted calyces. Few of the calyces were feathery and moth-eaten. Upper pole infundibular stenosis was seen. Midpolar calyx was also narrow. The right ureter was irregular in outline, tortuous however normal in calibre. Contrast outpouching was seen in the upper pole of right kidney and left Kidney (Fig. 1). Urine for mycobacterium bacilli was positive. Cystoscopy was done which suggested cystitis (Fig. 2).

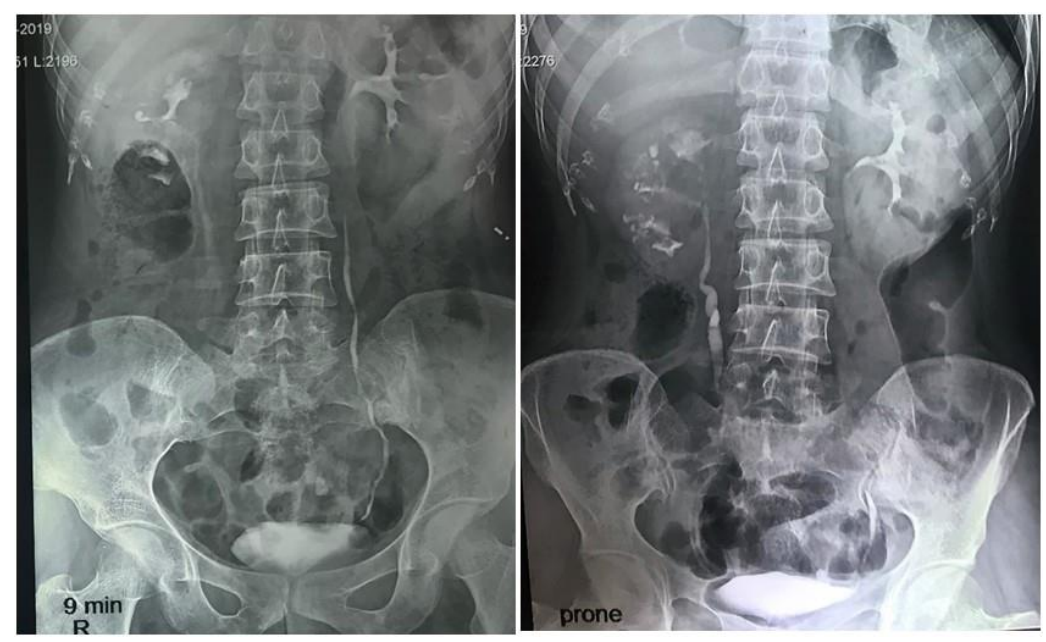

Figure 1: IVP film showed distorted calyces in right Kidney. Some of the calyces were feathery and moth-eaten in right kidney. Infundibular stenosis was seen in upper pole calyces. Midpolar calyx was also narrow in right kidney. The right ureter was irregular in outline, tortuous however normal in calibre. Upper pole of right kidney and left Kidney showed contrast outpouching. 


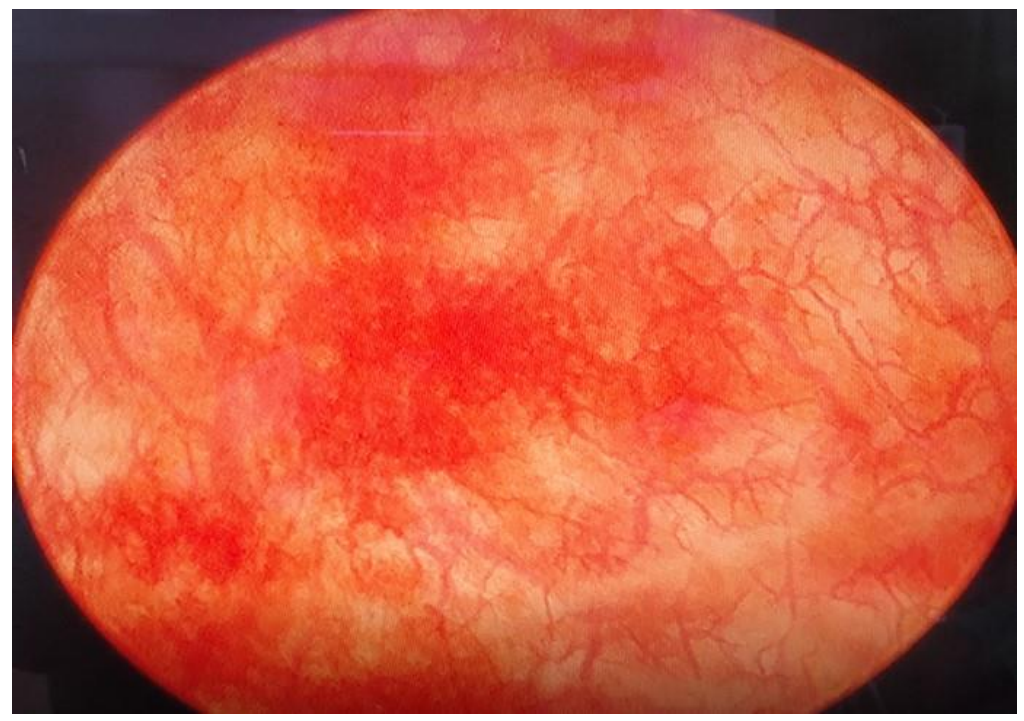

Figure 2: Cystoscopy suggest inflamed urinary bladder (Tubercular cystitis).

She was started on anti-tubercular drugs (ATT) and gradually improved. At 6 months follow up after ATT she was asymptomatic and urine for mycobacterium bacilli was negative.

Genitourinary tuberculosis is the second most common form of extrapulmonary tuberculosis with more than $90 \%$ of cases occurring in developing countries like India. Kidney is the most common organ involved followed by ureters, urinary bladder, etc. Intravenous pyelography provides anatomic details, functional extent, and severity of the disease. Although CT urography replaced IVP, it is still a very effective tool in upper urinary tract Kidneys and ureters. A short course of therapy comprising antitubercular drugs is very effective for genitourinary tuberculosis. Although some patients require minimally invasive procedures like DJ stenting, Percutaneous nephrostomy and few require reconstructive and ablative surgeries (Raina et al., 2021; WHO Global TB Report, 2019).

\section{References}

Raina P, Sharma GK, Kumar M, Barwal KC, Rana K, Chauhan S. Genitourinary tuberculosis: clinical profile, diagnostic approach and treatment outcome in a tertiary care center of North India. International Journal of Health and Clinical Research 2021; 4: 138-142.

WHO Global TB report (2019). www.who.int/teams/global-tuberculosis-progrmme/data 